\title{
Trust And Trustworthiness: A Game Theory Transcontinental Experiment
}

Wesley Pech, Wofford College, USA

Philip Swicegood, Wofford College, USA

\begin{abstract}
This article reports the results of a laboratory experiment that investigated differences in trust and trustworthiness between Americans and Croatians. Contrary to the majority of previous crosscultural studies, this experiment implemented a design that allowed participants to simultaneously interact with subjects from the other country. Additionally, it analyzed changes in their levels of trust and trustworthiness when information about the nationality of a subject's counterpart was not revealed. The main findings are: 1) Overall, Croatians trusted more than Americans did, but Americans were more trustworthy, 2) Subjects from both nationalities trusted less when they knew they were paired with somebody from another country, compared to when they interacted with someone from the same country, 3) Croatians also became less trustworthy when they were paired with an American, but Americans became more trustworthy when they were paired with a Croatian, and 4) Uncertainty about the nationality of one's counterpart reduced both trust and trustworthiness for both nationalities, a result that suggests that, overall, not knowing the nationality of one person caused the subjects to behave as if this person was of a different nationality.
\end{abstract}

Keywords: Trust; Trustworthy; Game Theory; Ethics; International Business

\section{INTRODUCTION}

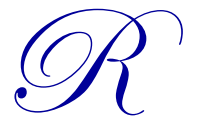

ecent advances in behavioral and experimental economics have expanded our understanding of human behavior in social interactions. Both laboratory and field experiments, for example, have shown that the model of self-regarding preferences, which assumes that people care only about their own material payoffs, cannot account for the observed actions of most subjects in these experiments when they faced environments that allowed for cooperation, coordination, bargaining, and trust (Camerer, 2003). These results have attracted a lot of attention, especially because they suggest that the basic assumption of purely selfish preferences, which has been the building block of many economic models that have tried to investigate social outcomes, is, at best, incomplete to explain social outcomes (Fehr and Fischbacher, 2002).

As an alternative to this assumption of purely self-regarding preferences, new theoretical models inspired by the results of these experiments have started to introduce other-regarding preferences (a.k.a. social preferences) into an agent's objective function in addition to the standard assumption of selfish motives (Fehr and Schmidt, 1999; Charness and Rabin, 2002). These models assume, in general, that in many different kinds of social interactions with strangers, humans do care about the outcomes, intentions, and actions of others around them, but in a conditional or reciprocal manner. The idea of reciprocity stipulates that humans are willing to be nice and cooperative toward those who are also being nice and cooperative, but at the same time, we are willing to behave in a hostile manner toward those who violate the social norm (Fehr and Gaechter, 2000). It is a propensity to be kind or unkind, conditional on the action of others, even when it is costly for us to do so and when there are no opportunities for future interactions (Gintis et al., 2008).

Even though a great deal has been learned about social preferences, little is known about other social inclinations that may interact with these preferences and that have an enormous influence in our daily lives, such as trust, honesty, and cultural conventions. This article addresses the topic of trust and trustworthiness by reporting the 
results of a series of laboratory experiments in two different countries (United States and Croatia). These experiments investigated how different types of interactions in these countries affect the beliefs that agents have about the behavior of other agents (from the same nationality and from another nationality). This preferential treatment to trust is justified given the importance that trust has in reducing transaction costs in any given economy. It is well known that differences in the levels of trust in a specific population are correlated with higher levels of economic growth, less income inequality, lower crime rates, and other desirable socioeconomic indicators (Cardenas and Carpenter, 2008). ${ }^{1}$

This study makes two methodological contributions to the literature: 1) the subjects had the opportunity to simultaneously interact with participants from the other country and 2) one of the treatments introduced uncertainty about the nationality of a subject's counterpart, wherein a person from one nationality was paired with another person, but she did not know the nationality of this person (the only information provided was that there was a 50-50 chance of being paired with one of these two nationalities). To the author's knowledge, this is the first study to combine these two treatments in the analysis of trust. ${ }^{2}$

The introduction of incomplete information about the nationality of one's counterpart into one of the treatments allowed us to answer how beliefs about trust change when this information is not available to the person making a decision. In a globalized and highly inter-connected world, the probability of interacting with strangers of unknown nationality increases significantly, and when these interactions do occur, opportunities for cooperation and trust are usually present. Many cross-cultural experiments investigating trust have been conducted in recent years. Most of these studies, however, have not allowed for the simultaneous interaction of people from different countries and have not included a treatment with incomplete information.

The main results are:

1. Overall, Croatians trusted more than Americans, but Americans were more trustworthy, especially when they knew they were interacting with a subject from Croatia.

2. Croatians reduced their levels of trust and trustworthiness when they were paired with an American compared to their levels of trust when they interacted with another Croatian.

3. Americans also reduced their levels of trust when they were paired with a Croatian, but surprisingly, they became more trustworthy toward a Croatian than when they interacted with another American.

4. Incomplete information regarding the nationality of the other person reduced both trust and trustworthiness in both countries.

\section{EXPERIMENTAL DESIGN}

A total of 108 subjects ( 54 from the United States and 54 from Croatia) participated in this experiment. The subjects were members of two institutions of higher education from these two countries (Wofford College, located in the United States and the University of Spit, located in Croatia). All treatments were anonymous; i.e., the subjects did not know the identity of their counterpart (even when they knew their nationality) and all sessions used monetary payoffs to create real incentives for the subjects to take the experiment seriously and to reveal their preferences in a more consistent manner. Each session took about 45 minutes to complete and subjects earned, on average, $\$ 16$ each. $^{3}$ Written instructions were provided to all subjects. All treatments were conducted in computer labs with the help of software that recorded and reported all decisions made by the subjects. In this paper, we acknowledge that even though the results did show a consistent pattern of behavior across treatments, the amount of statistical power that we had available was limited given our sample size.

\footnotetext{
${ }^{1}$ It is still debatable, however, what the direction of causation is.

${ }^{2}$ The only study that we are aware of that allowed subjects form different countries to interact simultaneously is Boarini et al. (2009), which investigated differences of behavior between subjects from India and France using an Ultimatum Game.

${ }^{3}$ Naturally, the final earnings of each subject differed significantly since the final payoffs depended on the decisions made by them and their counterparts.
} 
Berg et al. (1995) were the first to analyze this two-person sequential game, which allows the investigation of trust and trustworthiness in a specific group. In this game, subjects are brought to the lab and divided randomly into anonymous pairs (they know they have been paired with somebody, but they do not know who she is). Both persons receive an endowment of money. Person A - the first mover - has to decide how much of this endowment to transfer to Person B - the second mover. Any integer amount between 0 and the endowment is permitted. The amount transferred by Person A to Person B, however, is tripled by the experimenter before reaching the hands of Person B. After receiving this tripled amount, Person B decides how much (if any) of the total amount of money that she has (the initial endowment she received plus the tripled amount) she wants to transfer back to Person A. The amount transferred back to Person A by Person B is not tripled. Consider the following numerical example: Assume that both players start with $\$ 10$ and Person A chooses to transfer $\$ 6$ to Person B. Person A now has only $\$ 4$ and Person B has $\$ 28(\$ 10+(3 \times \$ 6))$. Person B now has to choose how much of this $\$ 28$ to transfer back to Person A. If Person B chooses to transfer back $\$ 3$, Person A earns a final payoff of $\$ 7(\$ 4+\$ 3)$ and Person B earns a final payoff of $\$ 25$ (\$28 - \$3).

If one assumes purely self-regarding preferences, the theoretical prediction of this game is straightforward regardless of what Person B receives, she will not transfer anything back to Person A if she is purely selfish because she has no obligation of transferring back a positive amount. Using backward induction, Person A anticipates that this is what a selfish second mover does and, by being selfish herself, she chooses to transfer nothing to Person B. It is important to notice that this prediction generates an inefficient set of payoffs. Both players could be better off if Person A had trusted Person B by transferring a positive amount to her and then Person B behaved in a trustworthy manner by transferring back to Person A at least the same amount that Person A transferred to her. For example, if they both start with $\$ 10$, the theoretical prediction under self-regarding preferences is that they will both leave the experiment with $\$ 10$; but if Person A transfers all $\$ 10$ to Person B, Person B will have $\$ 40(10+(3 \times \$ 10))$, and if Person B decides to transfer $\$ 20$ back to Person A, they will both leave the experiment with $\$ 20$, which is an outcome superior to both players.

In this game, we measure trust by observing how much first movers choose to transfer to second movers and we measure trustworthiness by observing how much second movers transferred back to first movers.

The empirical evidence of the Trust Game shows, in general, that most humans are willing to trust others by transferring a positive amount to second movers who, in turn, are usually willing to reciprocate by transferring a positive amount back to the first mover, typically enough to give the first mover at least the same payoff that she started the game with. However, in addition to this general finding, many studies have found a significant amount of cultural variation in this game where subjects from countries with higher rates of GDP growth, lower levels of poverty, and less inequality trust others more when they play this game compared to subjects from countries with the opposite characteristics (Cardenas and Carpenter, 2005).

Our experimental design implemented the Trust Game using both American and Croatians subjects to analyze trust and trustworthiness in three treatments: 1) Same nationality (Americans paired with Americans and Croatians paired with Croatians), 2) Other nationality (Americans paired with Croatians and vice-versa), and 3) Random pairing with uncertainty about the counterpart's nationality. Each subject played the same role (first mover or second mover) throughout the session and participated once in each treatment (a within-subjects design), which added to a total of three decisions per participant per experimental session. In order to avoid ordering effects, first movers did not receive immediate feedback about the amount that the second mover transferred back to them in each treatment. At the end of the experimental session, a message appeared on the computer screen showing the information about what second movers did to first movers in these three treatments. In each treatment, all subjects started the game with 10 Experimental Units (EU) $($ EU $4=\$ 1)$.

\section{RESULTS}

\section{Trust}

As mentioned in the Introduction, in the Trust Game, the amount transferred by the First Mover is an indication of the amount of trust that this person has toward an anonymous stranger. If one rules out the possibility 
of unconditional altruism in this game (giving a positive amount to a person who starts with the same endowment as yours, but without the intention of receiving anything back), the only explanation for transferring a positive sum of money to the Second Mover is that the First Mover has the belief that the Second Mover will reciprocate this action and transfer back at least the same amount that the First Mover chose to transfer to the Second Mover. We call this belief "trust.

\begin{tabular}{|l|c|c|}
\hline \multicolumn{2}{|c|}{ Table 1: Average Amount Transferred by First Movers } \\
\hline \multirow{3}{*}{ Same } & Americans & Croatians \\
\cline { 2 - 4 } Other & 5.04 & 9.07 \\
Uncertain & 5.96 & 7.43 \\
\end{tabular}

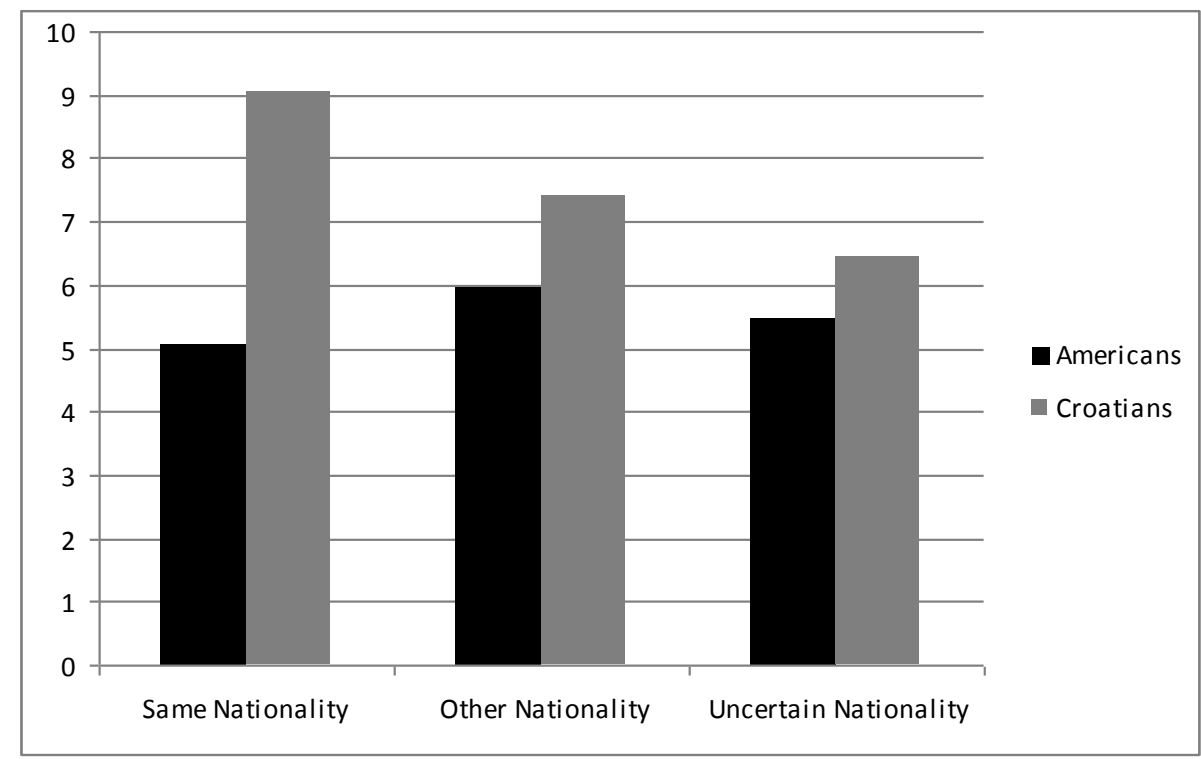

Figure 1: Average Amount Transferred By First Movers By Treatment And By Nationality

Table 1 and Figure 1 (the vertical axis) show the average amount transferred by First Movers, segregated both by nationality and by treatment. Overall, Croatians trusted more than the Americans. In all treatments, the average amount transferred by Croatians was higher than the average amount transferred by the Americans. By combining all three treatments, the difference is highly statistically significant (Mann-Whitney U Test - All treatments combined: $\mathrm{z}=2.85, \mathrm{p}=0.0037)$. When the treatments are segregated, the only statistically significant difference is for the Same Nationality treatment (Mann-Whitney U Test - Same Nationality: $z=2.91, p=0.003$; Other Nationality: $\mathrm{z}=0.79, \mathrm{p}=0.433$; Uncertain Nationality: $\mathrm{z}=0.729, \mathrm{p}=0.473$ ). Therefore, even though, overall, Croatians trusted more than the Americans, especially when they interacted with another person from the same country, we fail to reject the hypothesis that there is no difference in the levels of trust between Americans and Croatians when they are paired with a person from the other country and when they are not sure of the nationality of the other person.

The comparison between different treatments, holding the nationality of the subject constant, is also of interest. Croatians reduced their levels of trust significantly when they were either paired with an American or in the Uncertain Nationality treatment $(\mathrm{z}=2.85, \mathrm{p}=0.004$, and $\mathrm{z}=3.96, \mathrm{p}<0.000$, respectively). Americans, on the other hand, increased their levels of trust when they were paired either with a Croatian or in the Uncertain Nationality treatment, but these differences were not statistically significant $(\mathrm{z}=0.70, \mathrm{p}=0.48$, and $\mathrm{z}=0.37, \mathrm{p}=0.71$, respectively), so we fail to reject the null hypothesis that there is no change in trusting behavior when Americans have the possibility of interacting with a person from another nationality. 


\section{Trustworthiness}

It was argued in the Introduction that while the amount transferred by First Movers is a measure of trust, the amount transferred back by the Second Mover to the First Mover is a measure of trustworthiness. Trustworthiness is defined here as the feeling of reciprocity that is conditional on the amount of trust received by the other person. Table 2 and Figure 2 both show the average amount that was transferred back by Second Movers in each treatment for each country. In the Same Nationality treatment, the difference in the levels of trustworthiness were not statistically significant $(\mathrm{z}=1.48, \mathrm{p}=0.14)$. In the Other Nationality treatment and the Uncertain Nationality treatment, Americans were significantly more trustworthy than Croatians $(\mathrm{z}=2.35, \mathrm{p}=0.018$, and $\mathrm{z}=$ $1.97, \mathrm{p}=0.048$, respectively). Combining the three treatments, the difference in the levels of trustworthiness is marginally statistically significant $(\mathrm{z}=1.744, \mathrm{p}=0.08)$.

\begin{tabular}{|l|c|c|}
\hline \multicolumn{3}{|c|}{ Table 2: Average Amount Transferred back by Second Movers } \\
\hline \multirow{3}{*}{ Same } & Americans & Croatians \\
Other & 10.19 & 11.96 \\
Uncertain & 12.83 & 5.58 \\
\hline
\end{tabular}

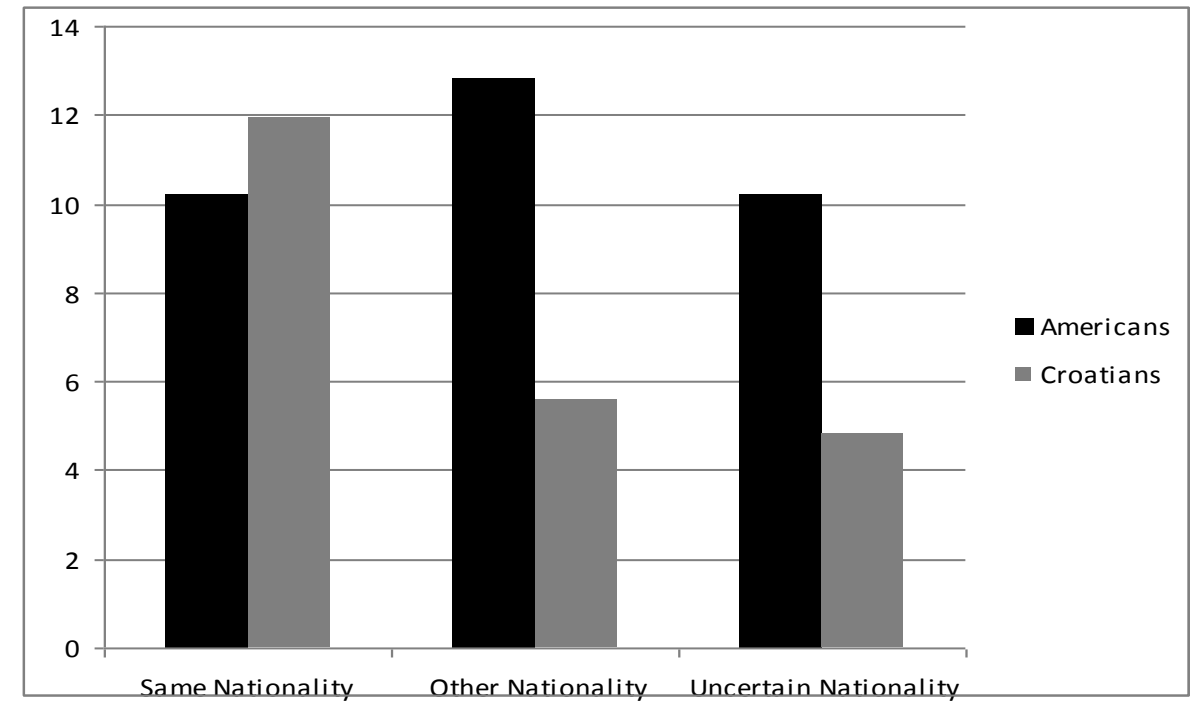

Figure 2: Average Amount Transferred Back By Second Movers By Treatment And By Nationality

These statistically significant differences, however, may not represent the precise levels of trustworthiness because the amount that each group of Second Movers received was certainly different. In the Other Nationality treatment, for example, Croatians transferred, on average, 7.43 to the Americans, whereas the Americans transferred, on average, only 5.96 to the Croatians. One can argue, then, that the fact that Americans transferred back more than Croatians is explained by the different levels of trust that they received. We control for this possibility by calculating two variables: 1) the average percentage of the initial transfer that was transferred back to First Movers by Second Movers and 2) the percentage of Second Movers who transferred back at least the same amount that was transferred to them by the First Movers. These two variables are shown in Tables 3 and 4 and Figures 3 and 4. Indeed, the results indicate that, with the exception of the Same Nationality Treatment, Americans were actually more trustworthy than Croatians.

Table 3: Percentage Of Amount Transferred By First Movers That Was Transferred Back By Second Movers

\begin{tabular}{|l|c|c|}
\hline \multirow{2}{*}{ Same } & Americans & Croatians \\
\cline { 2 - 3 } Other & $202.18 \%$ & $131.86 \%$ \\
Uncertain & $172.68 \%$ & $93.62 \%$ \\
& $154.86 \%$ & $91.51 \%$ \\
\hline
\end{tabular}




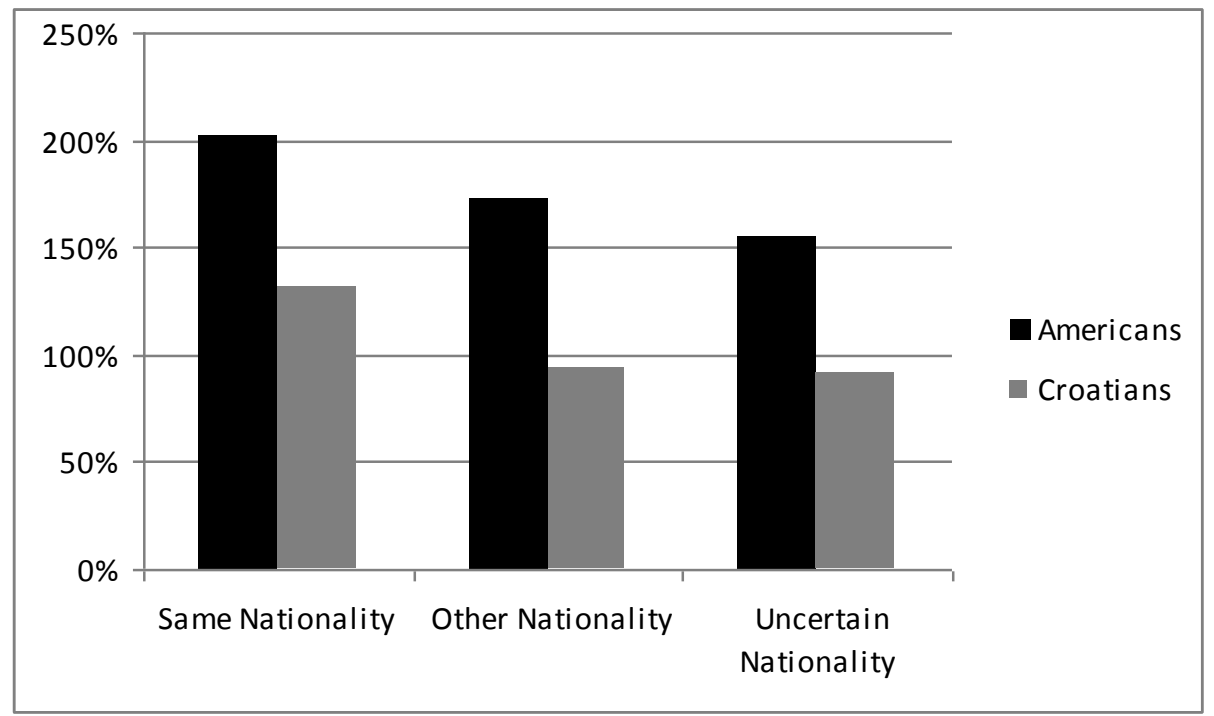

Figure 3: (100 x (Amount Transferred Back/Amount Transferred))

\begin{tabular}{|l|c|c|}
\hline \multicolumn{2}{|c|}{ Table 4: Percentage Of Second Movers Who Returned At Least The Same Amount That Was Transferred To Them By } \\
First Movers
\end{tabular}

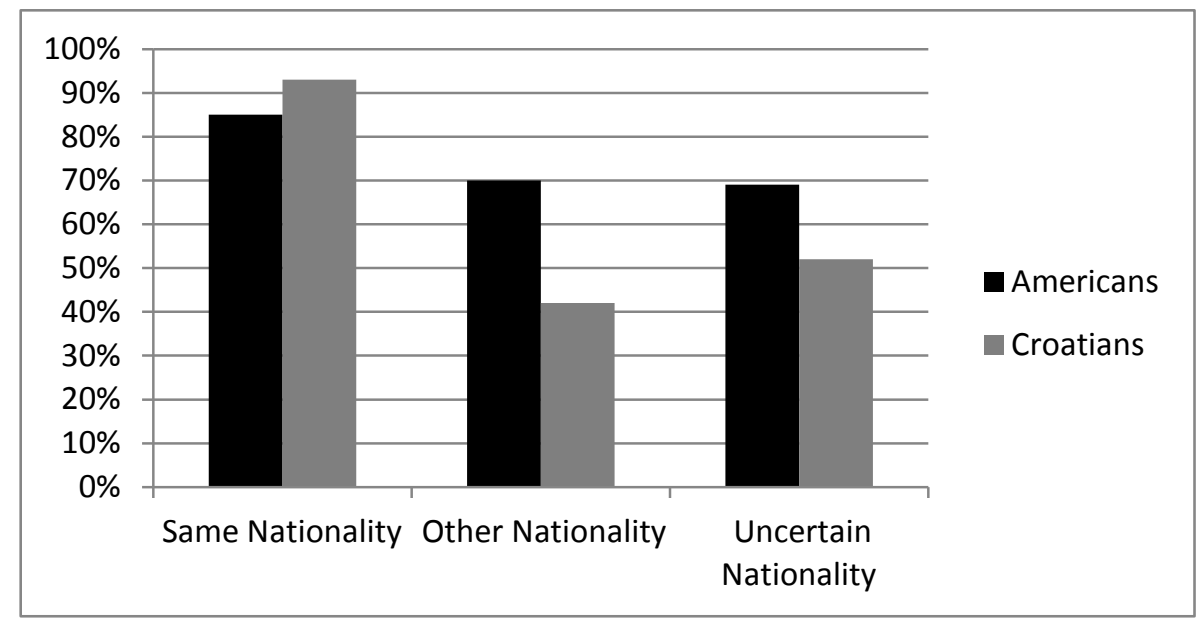

Figure 4: Percentage Of Second Movers Who Returned

At Least The Same Amount That Was Transferred To Them By First Movers

\section{CONCLUSION}

The investigation of the determinants of trust and trustworthiness is of significant importance to understand how institutions and social norms are maintained in a specific social environment; and, as the world becomes more globalized, it seems that these social interactions will be formed by people who never saw each other and might not even know the nationality of other participants. This study reported the results of a laboratory experiment that compared differences in levels of trust and trustworthiness between subjects from the United States and Croatia. The experiment made two novel contributions by allowing subjects to simultaneously interact with participants from the other country and by introducing uncertainty about a counterpart's nationality in order to try to understand what 
kinds of beliefs are formed when decisions have to be made under these circumstances. The results suggest that subjects from these countries did behave differently in the Trust Game. Whereas Croatians, overall, trusted more than Americans, Americans were more trustworthy. Somewhat surprisingly, Americans were more trustworthy to Croatians than they were to Americans and not knowing whether the person you are interacting with is from the same nationality as yours or not caused subjects from both countries to behave as if the other person was from a different nationality. Given that many different types of experiments have been conducted with the goal of understanding social preferences, we think that other experiments that follow the same methodology used in this article in a cross-cultural environment would make a significant contribution to the field of behavioral economics.

\section{ACKNOWLEDGEMENT}

The authors thank the Fulbright Program, Wofford College, and the University of Split for their sponsorship of this research. The authors also thank Mauricio Maurer for his contribution in developing the software that was used in this experiment.

\section{AUTHOR INFORMATION}

Wesley Pech is Assistant Professor of Economics at Wofford College. He specializes in game theory research, and holds a Ph.D. in Economics from University of Massachusetts - Amherst.

Philip Swicegood is the R. Michael James Professor of Finance at Wofford College. He holds a Ph.D. in finance from Florida State University and an MBA from the University of Texas at Austin. He has worked in the banking industry for the Office of the Comptroller of the Currency, and served as a Fulbright Scholar. E-mail: swicegoodpg@wofford.edu (corresponding author).

\section{REFERENCES}

1. Berg, Joyce. et al. (1995). "Trust, Reciprocity, and Social History." Games and Economic Behavior, 10(1), $122-42$.

2. Boarini, Romina, Jean-Francois Laslier, and Stephane Robin (2009). "Interpersonal Comparisons of Utility in Bargaining: Evidence from a Transcontinental Ultimatum Game." Theory and Decision, 67, 341-373.

3. Camerer, Colin (2003). "Behavioral Game Theory: Experiments in Strategic Interactions." Princeton University Press.

4. Cardenas, Juan Camilo and Jeffrey Carpenter (2005). "Behavioral Development Economics: Lessons from Field Labs in the Developing World." Journal of Development Studies, 44(3), 311-338.

5. Charness, Gary and Matthew Rabin (2002). "Understanding Social Preferences with Simple Tests." Quarterly Journal of Economics, 117(3), 817-869.

6. $\quad$ Fehr, Ernst and Klaus Schmidt (1999). "A Theory of Fairness, Competition, and Cooperation." Quarterly Journal of Economics, 114(3), 817-868.

7. $\quad$ Fehr, Ernst and Simon Gaechter (2000). "Fairness and Retaliation: The Economics of Reciprocity." Journal of Economic Perspectives 14(3), 159-181.

8. $\quad$ Fehr, Ernst and Urs Fischbacher (2002). "Why Social Preferences Matter." Economic Journal, 112, 1-33.

9. Gintis, Herbert. et al. (2008). "Strong Reciprocity and the Roots of Human Morality." Social Justice Research, 21(2), 1-13 
NOTES 